\title{
National survey of do not attempt resuscitation decisions on out-of-hospital cardiac arrest in China
}

\author{
Sijia Tian, Shengmei Niu, Luxi Zhang, Huixin Lian, Ming Zhou, Xuejiao Zhang, Xuqin Kang and JinJun Zhang*
}

\begin{abstract}
Background: To investigate and understand the determinants of decisions not to attempt resuscitation following out-of-hospital cardiac arrest, to contribute to establishing rules that are appropriate to China.

Methods: We recruited participants through directors of emergency medical services across China. A 28-question web survey was available between February 5 and March 6, 2021 that targeted demographic information and views on emergency work and cardiopulmonary resuscitation. Each question was assigned a value between 1 and 7 based on the level of importance from low to high. T-tests, one-way analysis of variance, and Kruskal-Wallis H-tests were used to compare continuous variables. Binary logistic regression analysis was used to identify factors influencing when people considered it suitable to initiate cardiopulmonary resuscitation.

Results: The study involved 4289 participants from 31 provinces, autonomous regions and municipalities in mainland China, of whom $52.8 \%$ were male. The top three reasons for not attempting cardiopulmonary resuscitation were decomposition/hypostasis/rigor mortis ( $6.39 \pm 1.44$ points), massive injury ( $4.57 \pm 2.08$ points) and family members' preference (4.35 \pm 1.98 points). In total, 2761 (64.4\%) thought emergency services should not attempt cardiopulmonary resuscitation when cardiac arrest had happened more than $30 \mathrm{~min}$ before, and there had been no bystander cardiopulmonary resuscitation. Gender (OR 1.233, $p=0.002$ ), religion (OR 1.147, $p=0.046$ ), level (OR 0.903, $p=0.028$ ) or classification of city (OR $0.920, p=0.049)$, years of work experience (OR $0.884, p=0.004)$, and major (OR $1.032, p=0.044$ ) all influenced how long after cardiac arrest was considered suitable for initiating cardiopulmonary resuscitation.
\end{abstract}

Conclusions: Chinese emergency physicians have different perceptions of when not to attempt resuscitation to those practicing elsewhere. The existing guidelines for resuscitation are not suitable for China, and China-specific guidelines need to be established.

Keywords: National survey, Do not attempt resuscitation, OHCA, Emergency medical services

\section{Background}

"Do not attempt resuscitation" and "do not attempt cardiopulmonary resuscitation" decisions allow cardiopulmonary resuscitation to be withheld where it stands little or no chance of success, when the risks outweigh the benefit

*Correspondence: zhang92560@163.com

Beijing Emergency Medical Center, Beijing 100031, China or if someone asks not to receive cardiopulmonary resuscitation [1]. Making non-resuscitation decisions is a complicated process with both moral and legal implications [2], especially in out-of-hospital cardiac arrest, which is a global public health problem with low survival rates [3]. Approximately 60,000, 300,000 and 550,000 people per year experience cardiac arrest out-of-hospital in England, the United States and China respectively [4-6]. Where 
these patients were treated by emergency medical services, resuscitation was not attempted for approximately 20.7\% in England, 10\% in the United States and 75.5\% in China $[4,5,7]$.

Emergency medical services play a critical role in management of cardiac arrest out-of-hospital, and may explain some of the variation in outcomes [8]. The emergency medical system in China is part of the healthcare system and supported by government. This is different from many other countries. In China, ambulances are usually staffed by a physician, a nurse and a driver, and the physician is responsible for resuscitation for almost all cardiac arrests out-of-hospital. The ambulance crews can perform both basic and advanced life support including provision of intravenous fluids, endotracheal intubation, defibrillation, mechanical ventilation, and drug therapy. Ambulances are often called "moving intensive care units" in China. By law, non-physicians cannot make the decision not to attempt resuscitation or to terminate resuscitation either inside or out-of-hospital. However, there are no rules about not resuscitating or termination of resuscitation for emergency medical services providers.

The objective of this study was to investigate and understand the determinants of decisions not to attempt resuscitation on cardiac arrests out-of-hospital, to contribute to developing rules appropriate to China.

\section{Methods}

\section{Study design and setting}

We used a web platform (Questionnaire Star, https:// www.wjx.cn/wjx/design/previewq.aspx?activity $=10661$ $8688 \& \mathrm{~s}=1$ ) for the survey. It was launched at $15: 00$ on February 5, 2021 and closed at 23:00 on March 6, 2021. We recruited 4318 participants using personal invitations sent through directors of emergency medical services across China and they all answered the questionnaire. The participants were all emergency physicians. We set an IP address that could only be used once, and the questionnaire could not be submitted if it was not filled in completely, to ensure validity and completeness. The time spent on each questionnaire was monitored automatically, and any questionnaires completed in fewer than $120 \mathrm{~s}$ were rejected as invalid. This study was approved by the Ethics Committee of Beijing Emergency Medical Center (2021-001) and written informed consent was waived. At the beginning of the survey, respondents were explicitly asked to give their consent to participate in the survey.

\section{Data collection}

A questionnaire was developed for the study and used to collect demographic information and views on emergency work and cardiopulmonary resuscitation. It included questions on gender, age, nationality, religion, education, major, years of work experience, and views on cardiopulmonary resuscitation and when not to resuscitate. We determined participants' geographic location using their IP addresses, and divided cities into first-, second-, and third-tier based on their level of economic development. Beijing, Shanghai, Guangzhou, and Shenzhen were first-tier cities. The $45 \mathrm{~s}$-tier cities were mainly provincial capital cities and more economically developed cities. All other cities were third-tier [9].

\section{Views on not attempting resuscitation}

We investigated why emergency physicians did not attempt cardiopulmonary resuscitation. We identified seven reasons from the literature and preliminary research, including decomposition/hypostasis/rigor mortis, massive injury, family members' preferences, the patient's expressed wishes, a medical history of serious illness, the patient's age, and no bystander cardiopulmonary resuscitation. Respondents selected and sorted the factors they considered important. Each option was assigned a value of 7 to 1 points by level of importance. If an option was not selected, it was assigned a value of 0 .

\section{Analysis}

Continuous variables were expressed as mean and standard deviation, and categorical variables were shown as frequency and percentage in each category. Differences between different levels of cities were tested using the Kruskal-Wallis H-test. Differences in views on when not to resuscitate by categorical variables were tested using t-tests or one-way analysis of variance. Kruskal-Wallis $\mathrm{H}$-tests were used when the variances were not uniform. Binary logistic regression analysis was used to identify the factors influencing how long after cardiac arrest was considered the cut-off for initiating cardiopulmonary resuscitation. All statistical analysis used SPSS version 22.0 (IBM Corp., Armonk, NY, USA), and $p<0.05$ was considered to be statistically significant.

\section{Results}

Of 4318 participants, 4289 (99.33\%) met the criteria. They were from 31 provinces, autonomous regions and municipalities in mainland China. In total, 2264 (52.8\%) were male and the largest proportion $(1907,44.5 \%)$ were between 30 and 40 years old. Most (3902, 91.0\%) were of Han nationality; 2862 (66.7\%) had an undergraduate degree; and 4080 (95.1\%) had no religious belief. A total of $1760(41.0 \%)$ worked in emergency medical services organisations at the prefecture level and 1767 (41.2\%) at county level or below. Just under half $(1946,45.4 \%)$ had been working for less than 5 years; 1528 (35.6\%) 
had majored in emergency medicine; and 2761 (64.4\%) thought cardiopulmonary resuscitation was inappropriate if the cardiac arrest had happened more than $30 \mathrm{~min}$ before, and there had been no bystander cardiopulmonary resuscitation (see Table 1 ).

\section{Comparison between different levels of cities}

In total, 1069 (24.9\%) participants were from first-tier, 1591 (37.1\%) from second-tier, and 1629 (38.0\%) from third-tier cities. There were significant differences between levels of city in gender $(\mathrm{H}=48.882, p<0.001)$, nationality $(\mathrm{H}=32.530, p<0.001)$, education $(\mathrm{H}=39.453$, $p<0.001)$, religion $(\mathrm{H}=6.932, p=0.031)$, level of city $(\mathrm{H}=95.036, p<0.001)$, years of work experience $(\mathrm{H}=14.171, p<0.001)$, and major $(\mathrm{H}=28.972, p<0.001)$ (Table 1).

\section{Comparison of views on whether to resuscitate}

The top reasons for not attempting resuscitation were decomposition/hypostasis/rigor mortis $\quad(6.39 \pm 1.44$

Table 1 Basic information of the investigator

\begin{tabular}{|c|c|c|c|c|c|c|}
\hline & $\begin{array}{l}\text { Total } \\
(N=4289)\end{array}$ & $\begin{array}{l}\text { First-tier city } \\
(N=1069)\end{array}$ & $\begin{array}{l}\text { Second-tier city } \\
(N=1591)\end{array}$ & $\begin{array}{l}\text { Third-tier city } \\
(N=1629)\end{array}$ & Statistic value & $\mathbf{P}$ \\
\hline Male(n,\%) & $2264(52.8)$ & $625(58.5)$ & $888(55.8)$ & $751(46.1)$ & 48.882 & $<0.001$ \\
\hline Age $(n, \%)$ & & & & & 3.939 & 0.140 \\
\hline$<30$ years & 1185(27.6) & $318(29.7)$ & $413(26.0)$ & $454(27.9)$ & & \\
\hline $31-40$ years & 1907(44.5) & 469(43.9) & $756(47.5)$ & 682(41.9) & & \\
\hline $41-50$ years & $980(22.8)$ & $227(21.2)$ & $359(22.6)$ & $394(24.2)$ & & \\
\hline $51-60$ years & $217(5.1)$ & $55(5.1)$ & $63(4.0)$ & $99(6.1)$ & & \\
\hline Han Nationality(n,\%) & 3902(91.0) & 1013(94.8) & 1450(91.1) & 1439(88.3) & 32.530 & $<0.001$ \\
\hline Education(n,\%) & & & & & 39.453 & $<0.001$ \\
\hline Master and above & $286(6.7)$ & $88(8.2)$ & 138(8.7) & $60(3.7)$ & & \\
\hline Undergraduate & $2862(66.7)$ & $674(63.0)$ & $1100(69.1)$ & 1088(66.8) & & \\
\hline Junior College and below & $1141(26.6)$ & $307(28.7)$ & $353(22.2)$ & $481(29.5)$ & & \\
\hline Religion(n,\%) & & & & & 6.932 & 0.031 \\
\hline No & 4080(95.1) & 1033(96.6) & 1507(94.7) & $1540(94.5)$ & & \\
\hline Buddhism & $140(3.3)$ & 20(1.9) & $65(4.1)$ & $55(3.4)$ & & \\
\hline Taoism & $9(0.2)$ & $1(0.1)$ & $5(0.3)$ & $3(0.2)$ & & \\
\hline Christian & $26(0.6)$ & $12(1.1)$ & $9(0.6)$ & $5(0.3)$ & & \\
\hline Islamic & $34(0.8)$ & $3(0.3)$ & $5(0.3)$ & $26(1.6)$ & & \\
\hline Level of city(n,\%) & & & & & 95.036 & $<0.001$ \\
\hline Provincial level & $762(17.8)$ & $333(31.2)$ & $261(16.4)$ & 168(10.3) & & \\
\hline Prefecture-level & $1760(41.0)$ & $319(29.8)$ & $756(47.5)$ & $685(42.1)$ & & \\
\hline County level and below & $1767(41.2)$ & $417(39.0)$ & $574(36.1)$ & $776(47.6)$ & & \\
\hline Work years $(n, \%)$ & & & & & 14.171 & 0.001 \\
\hline$<5$ years & 1946(45.4) & $547(51.2)$ & $720(45.3)$ & $679(41.7)$ & & \\
\hline $5-10$ years & $1130(26.3)$ & $238(22.3)$ & $419(26.3)$ & $473(29.0)$ & & \\
\hline $11-20$ years & $976(22.8)$ & 213(19.9) & $386(24.3)$ & $377(23.1)$ & & \\
\hline$>20$ years & $237(5.5)$ & $71(6.6)$ & $66(4.1)$ & $100(6.1)$ & & \\
\hline Major(n,\%) & & & & & 28.972 & $<0.001$ \\
\hline Internal Medicine & $971(22.6)$ & $286(26.8)$ & $381(23.9)$ & $304(18.7)$ & & \\
\hline Surgery & 499(11.6) & $81(7.6)$ & 203(12.8) & 215(13.2) & & \\
\hline Gynaecology and Obstetrics & $60(1.4)$ & $12(1.1)$ & $23(1.4)$ & $25(1.5)$ & & \\
\hline Pediatrics & $43(1.0)$ & $4(0.4)$ & $20(1.3)$ & $19(1.2)$ & & \\
\hline Emergency Medicine & 1528(35.6) & $240(22.5)$ & $588(37.0)$ & $700(43.0)$ & & \\
\hline General practice & $547(12.8)$ & $215(20.1)$ & $165(10.4)$ & $167(10.3)$ & & \\
\hline Other & $641(14.9)$ & $231(21.6)$ & $211(13.3)$ & 199(12.2) & & \\
\hline Time for DNAR(n,\%) & & & & & 5.494 & 0.064 \\
\hline $30 \mathrm{~min}$ & $2761(64.4)$ & $662(61.9)$ & 1019(64.0) & 1080(66.3) & & \\
\hline $60 \mathrm{~min}$ & 1528(35.6) & $407(38.1)$ & $572(36.0)$ & $549(33.7)$ & & \\
\hline
\end{tabular}


points), chosen by 4181 (97.5\%), massive injury (4.57 \pm 2.08 points), chosen by $3790(88.4 \%)$ participants and family members' preference ( $4.35 \pm 1.98$ points), chosen by 3843 (89.6\%) participants. The fourth to seventh reasons in order of preference were the patient's expressed views $(3.20 \pm 2.12$ points, 3470 participants, $80.9 \%)$, medical history of serious illness $(2.66 \pm 2.03$ points, 3096 participants, 72.2\%), the patient's age (2.05 \pm 1.85 points, 2896 participants, 67.5\%), and no bystander CPR $(1.08 \pm 1.32$ points, 2713 participants, 63.3\%) (Table 1 and Fig. 1).

For decomposition/hypostasis/rigor mortis, there were significant differences by gender, age, level and classification of city, and major (all $p<0.05$ ) (Table 2). Compared with being male and of Han nationality, women and nonHan nationalities considered decomposition/hypostasis/ rigor mortis less when deciding whether to attempt cardiopulmonary resuscitation. This factor was considered more important by those aged between 41 and 50 years than those in other age groups, and by those living in prefecture cities or second-tier cities. Those with a master's degree and above were more likely to consider decomposition/hypostasis/rigor mortis, as were those with 11 to 20 years of work experience. Compared with other religions, those who professed Taoism also focused more on this reason (Supplementary table).

\section{Binary logistic regression analysis}

Age, gender, nationality, level of education, religion, level and classification of city, years of work experience, and major were included in the logistic regression analysis. Factor values are shown in Fig. 2. Gender (OR 1.233, $p=0.002$ ), religion (OR 1.147, $p=0.046$ ), level (OR 0.903, $p=0.028$ ) and classification of city (OR 0.920, $p=0.049$ ), years of work experience (OR 0.884, $p=0.004$ ), and major (OR 1.032, $p=0.044$ ) all influenced how long after cardiac arrest it was considered appropriate to initiate cardiopulmonary resuscitation.

\section{Discussion}

The 2020 American Heart Association Guidelines Update for Cardiopulmonary Resuscitation and Emergency Cardiovascular Care provided only a few exceptions where withholding cardiopulmonary resuscitation would be considered appropriate [10]. The European Resuscitation Council Guidelines for Resuscitation 2015 also proposed that the decision not to start or to discontinue cardiopulmonary resuscitation is challenging out-of-hospital, because of the lack of information about patients' wishes and values, comorbidities and baseline health status [11]. In China, there are no guidelines or rules for withholding cardiopulmonary resuscitation, and the decision mainly relies on the judgement of physicians. The behaviour and views of doctors and patients in China are affected by traditional Chinese culture, and are often very different from those held elsewhere. Emergency ambulances in China are also usually staffed by a physician, a nurse and a driver, and any resuscitation is usually conducted by the physician. American Heart Association and European Resuscitation Council guidelines for resuscitation are therefore not necessarily applicable in China. This study investigated views on when to resuscitate among emergency medical services physicians from around China, as a way to establish suitable rules for China. To our knowledge, this is the first survey in China of doctors' views on when not to resuscitate. We found that the main factors influencing the decision not to perform cardiopulmonary resuscitation were decomposition/hypostasis/rigor mortis, massive injury, and family members' preferences. Most emergency physicians (64.4\%) would not perform cardiopulmonary resuscitation when cardiac arrest had occurred more than $30 \mathrm{~min}$ before and there had been no bystander cardiopulmonary resuscitation.

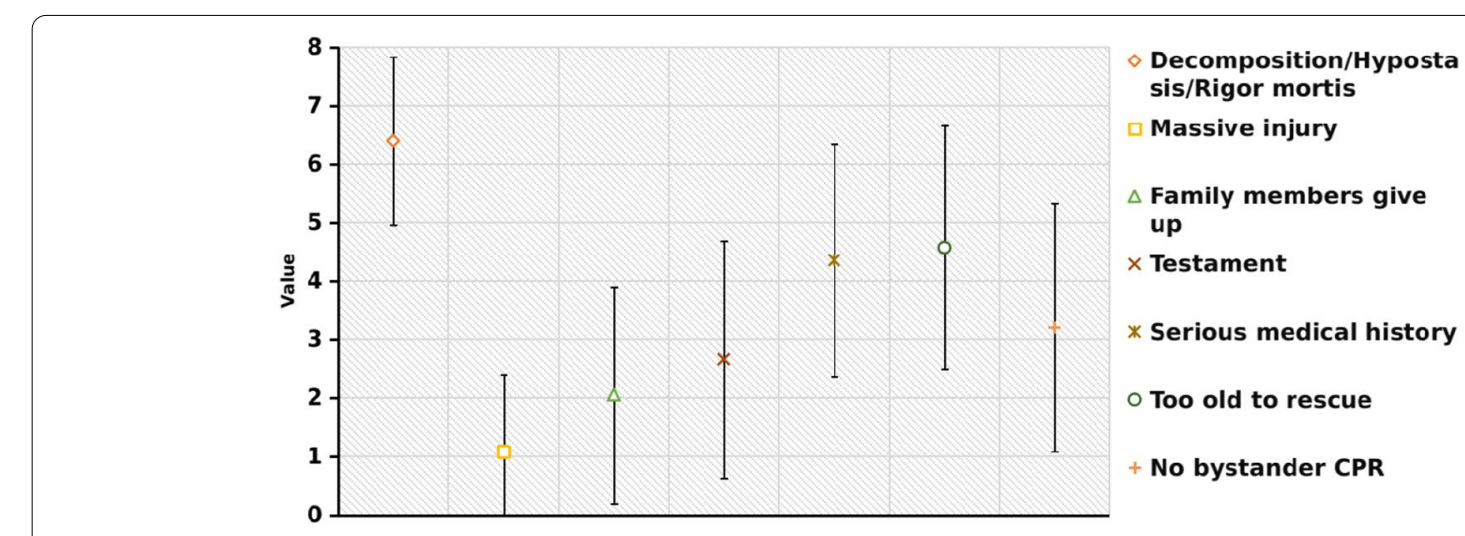

Fig. 1 Reason of DNAR sequence diagram 


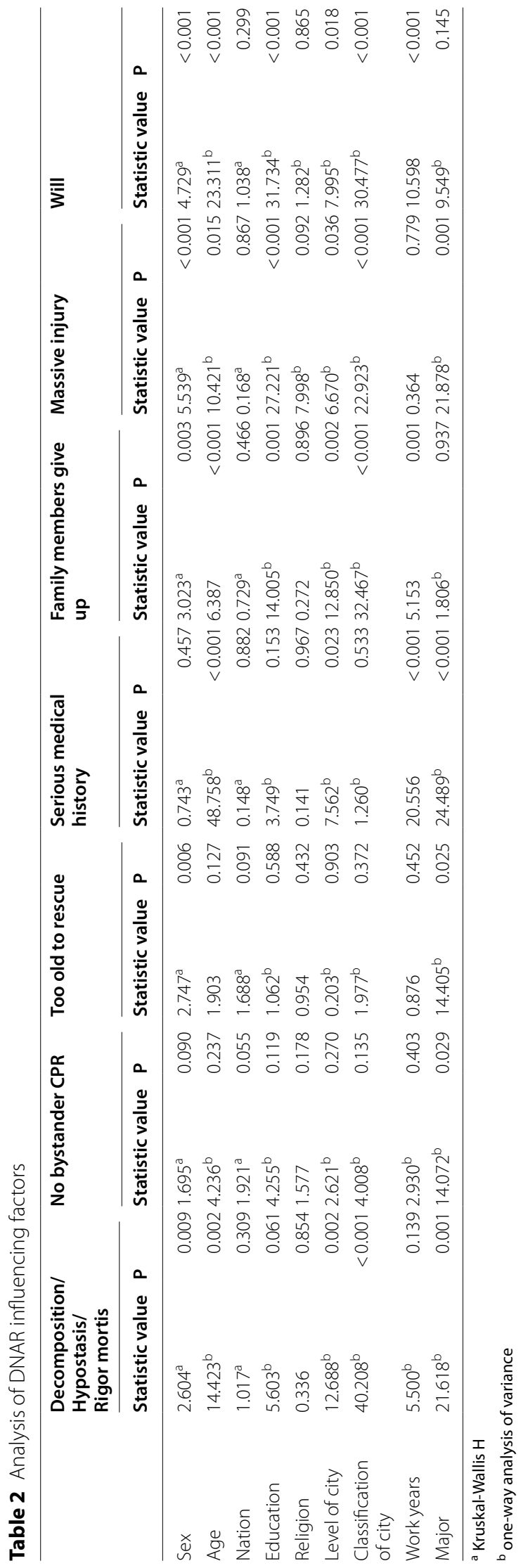




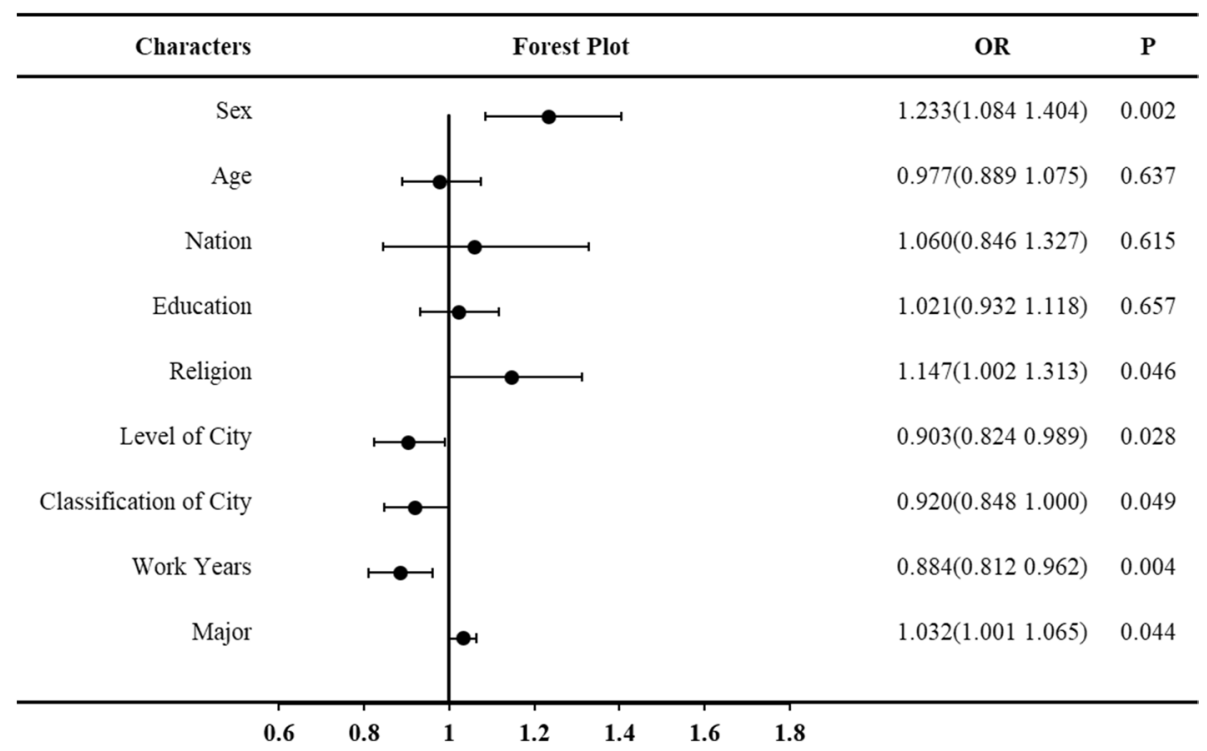

Fig. 2 Influence factors of how long after OHCA does not initiate cardiopulmonary resuscitation

The top two reasons for not attempting cardiopulmonary resuscitation were decomposition/hypostasis/rigor mortis and massive injury. In total, 4181(97.5\%) participants chose decomposition/hypostasis/rigor mortis, and $3226(75.2 \%)$ placed it first. A total of 3790 (88.4\%) participants chose massive injury, and 489 (11.4\%) placed it first. This is consistent with the guidelines proposed by the American Heart Association and The European Resuscitation Council [12-14]. Age, gender, level and classification of city and major were all factors that affected these two choices. Men and emergency physicians aged 41-50 were more inclined to make those choices.

In addition to the obvious signs of death, most emergency physicians also tended not to perform cardiopulmonary resuscitation when cardiac arrest had happened more than $30 \mathrm{~min}$ before. Women were more likely than men not to attempt resuscitation when time since arrest was more than $60 \mathrm{~min}$, as were emergency personnel with religious views. Physicians were less likely to attempt cardiopulmonary resuscitation more than $30 \mathrm{~min}$ after arrest with no bystander cardiopulmonary resuscitation when they worked for higher level emergency centres and in more prosperous cities. More experienced emergency personnel also thought that if cardiac arrest was more than $30 \mathrm{~min}$ ago, they should not give cardiopulmonary resuscitation. The guidelines for cardiopulmonary resuscitation in Europe, America and other countries suggest that cardiopulmonary resuscitation should not be initiated if the cardiac arrest was more than 15 min before. In China, physicians are therefore inclined to consider a longer time is more appropriate $[15,16]$, which is closely related to Chinese culture $[17,18]$.

Another important factor that affected views about whether to initiate cardiopulmonary resuscitation was the views of family members. This was ranked third in the survey. In China, emergency physicians will often respect the wishes of family members rather than consider the patient's situation, such as their age $[19,20]$. Even if a doctor's professional judgement is that cardiopulmonary resuscitation is not appropriate, they may provide it if family members strongly request it. When family members explicitly ask them to stop, emergency personnel will not implement cardiopulmonary resuscitation and other related treatment methods under any circumstances.

Other factors like the patient's expressed views, their medical history and age, and no bystander cardiopulmonary resuscitation also affected decisions about whether to perform cardiopulmonary resuscitation. These factors should also be considered as criteria for not providing cardiopulmonary resuscitation in the development of future guidelines for China.

This study had some limitations. First, the survey covered all provinces on the mainland, but the number of participants in some areas was relatively small. The survey may therefore not have fully captured the complexity of different responses to cardiac arrest out-of-hospital across China. Second, the order of the questions in the questionnaire was not randomised, so a learning effect in the course of responding to the questions cannot be excluded. Third, participants on web panels are more 
likely to be better educated, which could have affected the results. Last, we did not stratify by suspected mechanism or documented cardiac rhythm in our analysis due to inability to collect information. While case-control research is important direction for our follow-up, and we will definitely consider suspected mechanism and documented cardiac rhythm in our future study.

\section{Conclusions}

Chinese emergency physicians have different perceptions from their foreign colleagues about when to resuscitate patients after cardiac arrest. The existing guidelines for resuscitation are therefore not suitable for China, and China-specific guidelines need to be established.

\section{Abbreviations}

DNAR: Do not attempt resuscitation; OHCA: Out-of-hospital cardiac arrest; CPR: Cardiac Pulmonary Resuscitation; OR: Odds ratio.

\section{Supplementary Information}

The online version contains supplementary material available at https://doi. org/10.1186/s12873-022-00581-0.

Additional file 1: Supplementary table. Scores of factors affecting DNAR at different levels.

\section{Acknowledgements}

We thank all the EMS staff from mainland of China who participated in this survey and thank the Questionnaire Star (https://www.wjx.cn) for providing us with a data survey platfrom.

We thank Melissa Leffler, MBA, from Liwen Bianji (Edanz) (www.liwenbianji.cn) for editing the English text of a draft of this manuscript.

\section{Authors' contributions}

ST and JZ conceived and designed the study. LZ,ST and LH collected data. ST and SN analyzed data. ST and JZ wrote the first draft. MZ, XK, XZ and SN conducted the investigation. JZ and $\mathrm{YC}$ reviewed the draft. All authors read and approved the final manuscript.

\section{Funding}

This study was supported by The National Natural Science Foundation of China (81871455),Beijing Municipal Science and Technology Project (Z191100004419003). The content of these two projects are all about the investigation of cardiac arrest resources and provide help for research information collection. The National Natural Science Foundation of China (81871455) Project helped us find directors of emergency medical services and complete data collection. Beijing Municipal Science and Technology Project (Z191100004419003) approved the manuscript. The two projects work together to analyze and interpret the data.

\section{Availability of data and materials \\ http://doi.org/10.6084/m9.figshare.19076240}

\section{Declarations}

\section{Ethics approval and consent to participate}

The study was approved by Ethics Committee of Beijing Emergency Medical Center (No.2021-001) and the written informed consent was waived.Because at the beginning of the survey, respondents were explicitly asked to give their consent to participate in the survey.
Consent for publication

Not applicable.

\section{Competing interests}

The authors declare that they have no competing interests.

Received: 23 Auqust 2021 Accepted: 31 January 2022

Published online: 11 February 2022

References

1. Perkins GD, Griffiths F, Slowther AM, et al. Do not attempt cardiopulmonary resuscitation decisions: an evidence synthesis. Southampton (UK): NIHR Journals Library; 2016.

2. Fallahi M, Mahdavikian S, Abdi A, et al. Nurses and physicians'viewpoints about decision making of do not attempt resuscitation (DNAR). Multidiscip Respir Med. 2018;13:20.

3. Berdowski J, Berg RA, Tijssen JG, Koster RW. Global incidences of out-ofhospital cardiac arrest and survival rates: systematic review of 67 prospective studies. Resuscitation. 2010;81(11):1479-87.

4. Hawkes C, Booth S, Ji C, et al. Epidemiology and outcomes from out-ofhospital cardiac arrests in England. Resuscitation. 2017;110:133-40.

5. Counts CR, Blackwood J, Winchell R, et al. Emergency Medical Services and Do Not Attempt Resuscitation directives among patients with outof-hospital cardiac arrest. Resuscitation. 2021;158:73-8.

6. Xu F, Zhang Y, Chen YG. Cardiopulmonary resuscitation training in China:current situation and future development. JAMA Cardiol. 2017;2(5):469-70.

7. Shao F, Li CS, Liang LR, et al. Outcome of out-of-hospital cardiac arrests in Beijing. China Resuscitation. 2014:85:1411-7.

8. Hazinski MF, Nolan JP, Aickin R, et al. Part 1: Executive summary: 2015 international consensus on cardiopulmonary resuscitation and emergency cardiovascular care science with treatment recommendations. Circulation. 2015;132((16)(suppl 1):S2-39.

9. Jinhua Liu, Hongsheng Chen, Yang Chen, et al. Exploring the relationship between migrants' purchasing of commercial medical insurance and urbanisation in China. BMC Health Serv Res. 2018;18:679.

10 Panchal AR, Bartos JA, Cabañas JG, et al. Part 3: Adult Basic and Advanced Life Support: 2020 American Heart Association Guidelines for Cardiopulmonary Resuscitation and Emergency Cardiovascular Care. J Circulation. 2020;142:S366-468.

11 MonsieursKoenraad G, Nolan Jerry P, Bossaert Leo L, et al. European Resuscitation Council Guidelines for Resuscitation 2015: Section 1. Executive summary J Resuscitation. 2015;95:1-80.

12 Aung Myat, Kyoung-Jun Song, Thomas Rea. Out-of-hospital cardiac arrest current concepts. Lancet. 2018;391:970-9.

13. Ong MEH, Perkins GD, Cariou A. Out-of-hospital cardiac arrest: prehospital management. Lancet. 2018;391(10124):980-8.

14 Tatsuma Fukuda, Naoko Ohashi, Takehiro Matsubara, et al. Applicability of the prehospital termination of resuscitation rule in an area dense with hospitals in Tokyo: a single-center, retrospective, observational study: is the pre hospital TOR rule applicable in Tokyo? Am J Emerg Med. 2014;32:144-9

15. Jae Chol Y, Youn-Jung $K$, Shin A, et al. Factors for modifying the termination of resuscitation rule in out-of-hospital cardiac arrest. Am Heart J. 2019:213:73-80.

16 Keita Shibahashi, Kazuhiro Sugiyama, Yuichi Hamabe. A potential termination of resuscitation rule for EMS to implement in the field for out-of-hospital cardiac arrest: An observational cohort study. Resuscitation. 2018;130:28-32.

17. Zhou G, Lu G, Shi O, Li X, Wang Z, Wang Y, Luo Q. Willingness and obstacles of healthcare professionals to perform bystander cardiopulmonary resuscitation in China. Int Emerg Nurs. 2019;47:100788. https://doi.org/10. 1016/j.ienj.2019.100788 Epub 2019 Sep 4 PMID: 31494073.

18. Zhu N, Chen Q, Jiang Z, Liao F, Kou B, Tang H, Zhou M. A meta-analysis of the resuscitative effects of mechanical and manual chest compression in out-of-hospital cardiac arrest patients. Crit Care. 2019;23(1):100. https:// doi.org/10.1186/s13054-019-2389-6.PMID:30917840;PMCID:PMC6437862.

19. Zhan L, Yang $\sqcup$, Huang Y, He Q, Liu GJ. Continuous chest compression versus interrupted chest compression for cardiopulmonary resuscitation 
of non-asphyxial out-of-hospital cardiac arrest. Cochrane Database Syst Rev. 2017;3(3):CD010134.

20. Zhang L, Luo M, Myklebust H, Pan C, Wang L, Zhou Z, Yang Q, Lin Q, Zheng ZJ. When dispatcher assistance is not saving lives: assessment of process compliance, barriers and outcomes in out-of-hospital cardiac arrest in a metropolitan city in China. Emerg Med J. 2020;38(4):252-7.

\section{Publisher's Note}

Springer Nature remains neutral with regard to jurisdictional claims in published maps and institutional affiliations.

- fast, convenient online submission

- thorough peer review by experienced researchers in your field

- rapid publication on acceptance

- support for research data, including large and complex data types

- gold Open Access which fosters wider collaboration and increased citations

- maximum visibility for your research: over 100M website views per year

At BMC, research is always in progress.

Learn more biomedcentral.com/submissions 